\title{
Cascade hydropower systems optimal operation: implications for Iran's Great Karun hydropower systems
}

\author{
Saeed Jamali ${ }^{1}$ (D) Behzad Jamali ${ }^{2}$
}

Received: 17 April 2017 / Accepted: 15 March 2019 / Published online: 3 April 2019

(c) The Author(s) 2019

\begin{abstract}
Water resources optimal allocation in large complex water systems such as multi-reservoir dams is a challenging task for decision makers. Wide range of decision variables as well as difficult nonlinear optimization problems (highly nonlinear problems) make it difficult to use optimization approaches. Alternatively, simulation-optimization approaches are then providing more realistic and applicable solution. This study presents a simulation-optimization framework for extracting monthly long-term operation rules. This method is applied to Karun River Basin including six multi-objective (hydropower generation, agricultural and environmental water supplement) cascade dams. In this regard, Water Evaluation and Planning System is used as the simulation model coupled with an optimization model. Decision variables include (1) monthly variation of top of buffer parameter in reservoirs where the reservoir releases water to meet the required demand and (2) monthly priority for filling of the reservoirs. Two-objective NSGA-II algorithms are used to minimize sum of squares unmet energy and agricultural water demands within two scenarios. The results show that the reliability of the generation of hydroelectricity in Karun River Basin has been increased sufficiently. Results showed that the scenario 2 (an aggregate energy demand at the system level) has better performance in terms of reliability (91.4\% compared to $89.6 \%$ ) and efficiency of centralized approach in which all reservoirs are operated in an integrated management scheme.
\end{abstract}

Keywords Hydropower · Karun River basin · Multi-reservoir system operation · Simulation-optimization · WEAP . GANetXL

\section{Introduction}

Optimization techniques have been used widely in water resources planning and management studies, especially in reservoir operation problems. Reservoir operation is a complex problem that involves many decision variables, multiple objectives as well as considerable risks and uncertainties (Loucks 1997). Many of optimization models are not well performed in modeling large water systems. For example, the complexity of reservoir operation problem may arise from a combination of reservoirs in series parallel. Therefore, an

Saeed Jamali

sae.jamali@iauctb.ac.ir

1 Department of Civil Engineering, Islamic Azad University of Central Tehran Branch, Tehran, Iran

2 School of Civil and Environmental Engineering, University of New South Wales, Sydney, Australia appropriate management with more robust modeling tools (compared to the classic optimization models) is required.

The goal of optimization is to extract predefined rule curves that guide the release of the reservoir system based on the current storage level, the hydro-meteorological conditions and the time of the year (Ngo et al. 2007). In the spite of the development and growing use of optimization techniques, the vast majority of reservoir planning and operation studies are based on simulation modeling (Lund and Guzman 1999). The operation rules are often evaluated using simulation models (Loucks 1997). Optimization models still require important simplifications of the system in order to be solvable. Therefore, simulation models remain necessary to examine the detailed performance of system operation (Lund 2006).

Simulation could be the starting point in the planning of large-scale systems, but as it requires many complex configuration options, capacity and operating policy, simulation would be very time-consuming (Rani et al. 2008). An efficient approach for identifying well predefined operating 
rules for such complex multi-reservoir systems is to use both optimization and simulation models together (Sigvaldason 2010; Johnson et al. 1991). Those approaches use optimization techniques to search for the best operating policies, while the simulation model is used to test and refine the rules. This process may involve many optimization and simulation runs (Lund 2006).

Simulation-optimization technique has been used in different water systems management studies. Rani et al. (2008) and Fayaed et al. (2013) have comprehensively reviewed simulation, optimization and combined simulation-optimization modeling approaches and gave an overview of utility analysis of their previous studies. According to these reviews, by comparing semi-definite programming (SDP) and SDP within simulation processes, the latter approach has better performance in terms of operation policies for a multireservoir system (Tejada-Guibert et al. 1993). Randall et al. (1997) used mixed integer linear programming (MILP) for water supply planning in California. Later, Karamouz et al. (2004) used simulation-optimization approach for regional water resources assessments. Wang et al. merged simulation approach and decomposition replication in order to eliminate the multi-objective semi-definite programming optimization problems for reservoirs in parallel. Suiadee and Tingsanchali (2007) developed a software called "simulation-GA model" with a reasonable graphical capability for discovering the optimal rule curves of the reservoirs. A combined simulation-optimization modeling called "robust simulation-optimization modeling system (RSOMS)" was created by Zhang et al. (2013) for controlling agricultural non-point source (NPS) to discharge trade effluent.

Due to time-taking computational problem in multi-reservoir systems as well as modeling with longer time horizon, it is suggested to use meta-models such as artificial neural network (ANNs) which is less time-consuming for finding an optimal solution in complicated operation problems. For example, Shokri et al. (2013) proposed that non-dominated sorting genetic algorithm-II (NSGA-II-ANN) is an evolutionary algorithm applied in multi-objective optimization problem in spill of pollution situations.

The so-called approach can be used in groundwater studies as well. For example, Safavi et al. (2010) generated a simulation-optimization method for both surface and groundwater usage at the scale of basin. Sedki and Ouazar (2011) used a transient simulation model with the aim of determining the optimal pumping schemes in which the groundwater flow in a coastal aquifer is characterized by a genetic algorithm.

By applying a combination of MIKE 11(1-dimensional river model) simulation and an adopted shuffled complex evolution (SCE) optimization model, Ngo et al. (2007) estimated the amount of reservoir releases considering hydropower generation and flood control. Afzali et al. (2008) used a reliability-based simulation-optimization approach for a better design of multi-reservoir systems with hydropower purposes. A hybrid particle swarm optimization-modeling and simulation (PSO-MODSIM) model was applied by Shourian et al. (2008) to find the proper sizes of water storage and transmission facilities. (Malekmohammadi et al. 2010) linked Hydrologic Engineering Centers River Analysis System (HEC-RAS) model with genetic algorithm (GA) to determine the exact hourly release of a reservoir to reduce to a minimum flood damages in the downstream of a river. Ostadrahimi et al. (2012) offered some operational rules for a three-reservoir system in Columbia River Basin with the use of both multi-swarm version of particle swarm optimization (MSPSO) and Hydrologic Engineering Center's Prescriptive Reservoir Model (HEC-ResPRM) as a simulation model. Simulation-optimization methods have been used in several flood management studies. Eum and Simonovic (2010) and Eum et al. (2012) combined Hydrologic Engineering Center's Hydrologic Modeling System (HEC-HMS) with the differential evolution (DE) optimization algorithm for management's best strategy estimate of $t$ multi-reservoir system under climate change conditions. In addition to those researches, Hassaballah et al. (2012) created a methodology and coupled two simulation (MIKE BASIN) and optimization methodologies to find the filling rules for a reservoir which has the least impact on hydropower generation. Hassanjabar et al. analyzed the impacts of applying different policies in a multi-reservoir system on surface water quality by applying a simulation-optimization model under different environmental operating conditions (2018).

According to the literature discussed above, simulation-optimization approach has been tried out to overcome the complexities in water systems problems. That is the most important reason why a simulation-optimization model is proposed in this study in order to determine the appropriate monthly operation of a multi-reservoir system in Karun River Basin, Iran. Water Evaluation and Planning System (WEAP), which is developed by the Stockholm Institute (Yates et al. 2005), has been used as the simulation model in combination with GANetXL software as the multi-objective optimization tool. Reservoir operation policies are set up in WEAP to determine water allocation amounts with regards to the demands.

\section{Study area}

The Great Karun River's watershed with the area of almost 65,000 square kilometers is considered as the largest river by discharge in Iran. The river is $950 \mathrm{~km}$ long. Over 280,000 hectares is irrigated by Karun water. In recent years, nearly 100,000 ha is planned to receive water from this river (Khuzestan Water and Power Authority 2010). 
There are a number of dams on the Karun River called Gotvand Dam, Dez dam, Masjed Soleyman Dam, Karun-1, Karun-3, Karun-4 (Fig. 1), etc. These dams have specific purpose such as controlling floods, irrigation water storage and hydropower generation.

\section{Methodology and modeling approach}

\section{Simulation model}

WEAP is used as a comprehensive software for integrated water resources management and policy analysis (Yates et al. 2005). Data for the model are provided at monthly time steps for the period from October 1981 to September 2013 (396 time steps). As shown in the schematic view of Karun system in Fig. 2, the system consists of six reservoirs,

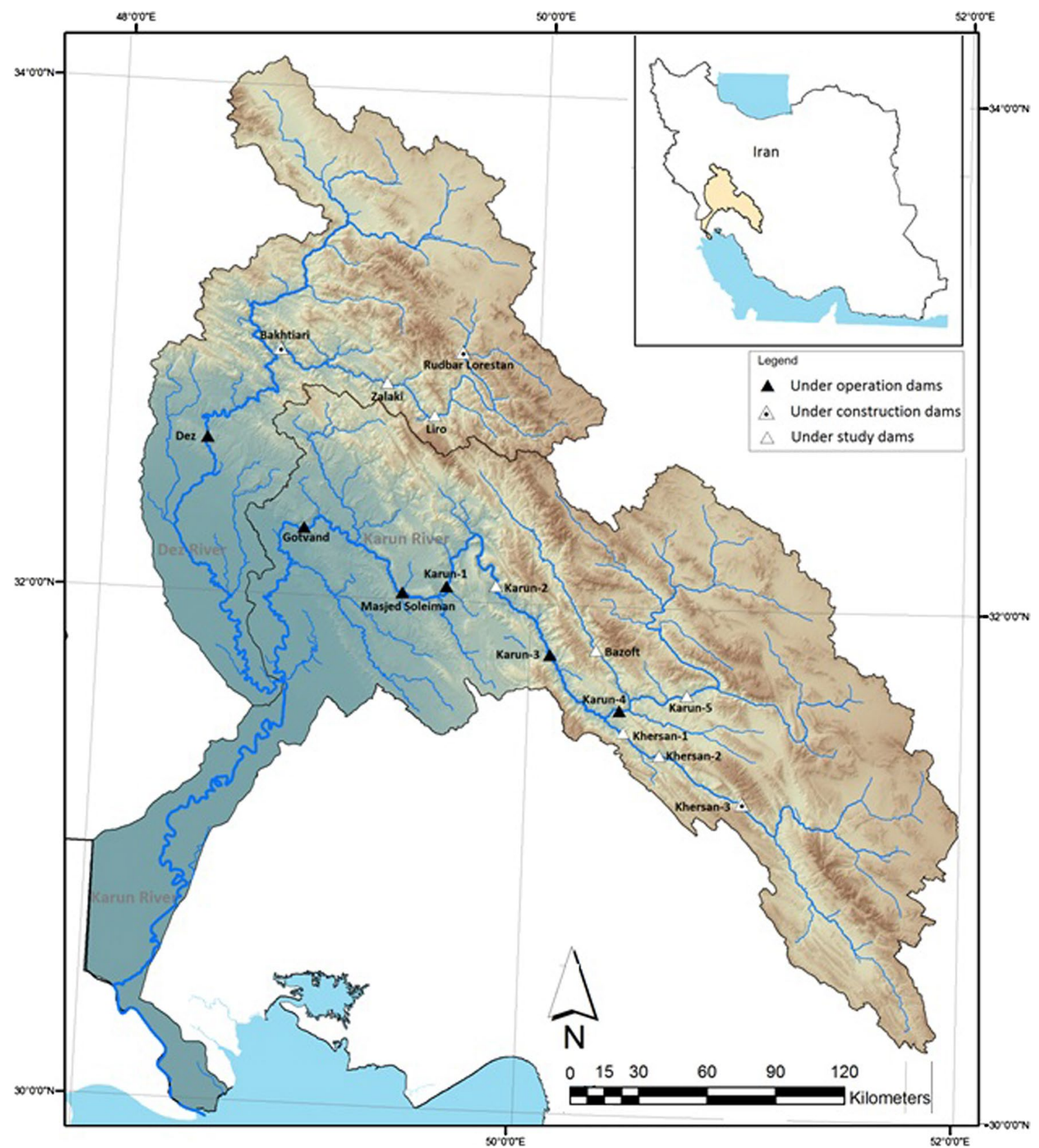

Fig. 1 Study area 
Fig. 2 Schematic view of reservoirs and demands sites in WEAP model

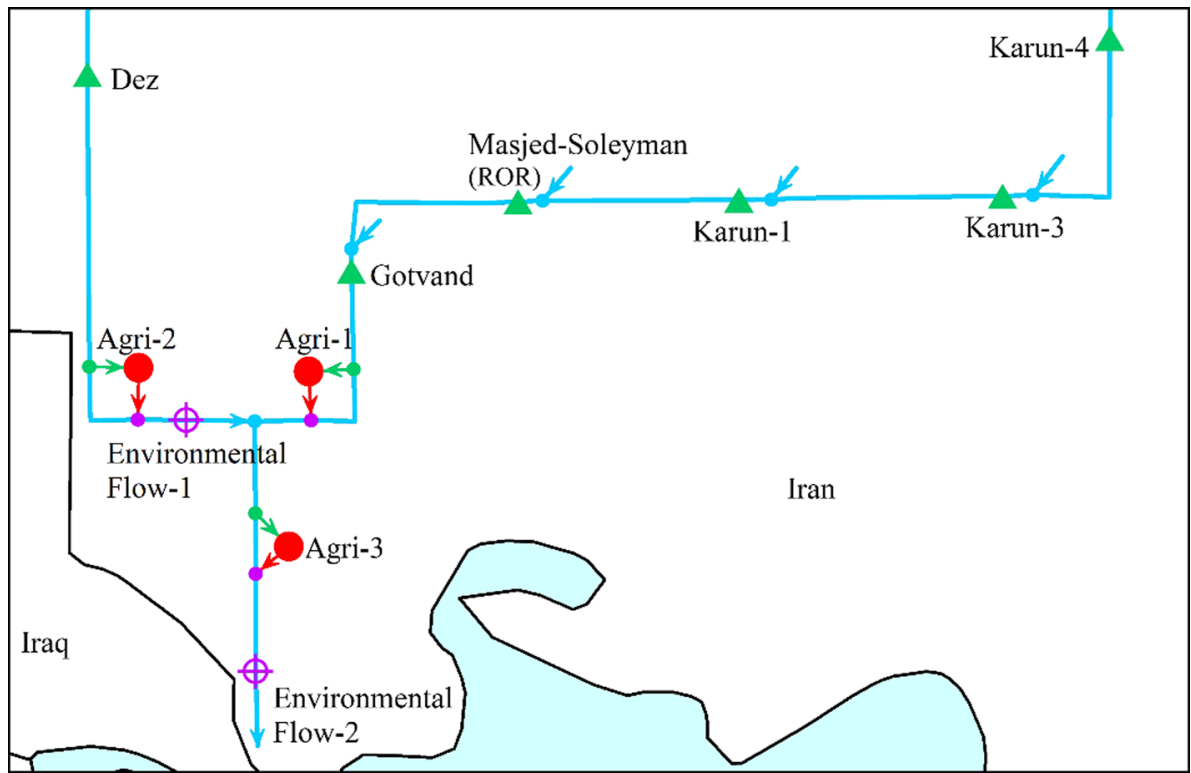

three agricultural demand sites (20\% return flow) and two environmental flow demands. Table 1 summarizes the general characteristics of dams in the study area. Among them, Masjed Soleyman is a run-of-river (ROR) hydroplant with 226 MCM storage capacity where water used in this manner is only for power generation. This reservoir is always operated at a constant volume between 222 to $226 \mathrm{MCM}$.

As Iranian national grid system requires, the reservoirs, studied in this paper, are designed to provide electricity during peak time. Energy demand from each reservoir is determined according to the analysis of their electricity generation in the last 5 years. In addition, each reservoir must supply a minimum amount of the energy demand which is defined by multiplying peak operating hours and installed capacity.

In this study, hydropower energy demands are categorized by two scenarios in WEAP:

1. Individual energy demands for each reservoir.

2. An aggregate energy demand at the system level.
Environmental flow requirements and hydropower energy and agricultural demands assign explicit priority positions (first and second priorities, respectively). The main problem of WEAP as a simulation model cannot store water for the next time steps. In other words, WEAP does not have intraseasonal allocation scheme in its algorithm. To solve this issue, top of buffer levels in reservoirs shall be increased. Moreover, in complex reservoir systems (series and parallels), the performance will vary by changing priorities. Lund and Guzman (1999) suggested some set of rules for systems with one objective. For the systems with multiple objectives, it is a time-consuming approach to find the monthly priorities. Therefore, the main purpose of optimization model is to find the best monthly values in order to maximize agricultural and hydropower energy demands.

\section{The optimization model}

GANetXL, which is an optimization add-in for Microsoft Excel $^{\circledR}$ (Deb et al. 2002), was used to minimize the unmet

Table 1 General characteristics of reservoirs

\begin{tabular}{|c|c|c|c|c|c|c|c|}
\hline Reservoir & $\begin{array}{l}\text { Installed } \\
\text { capacity } \\
\text { MW }\end{array}$ & $\begin{array}{l}\text { Peak operating } \\
\text { hours } \\
\text { Hours }\end{array}$ & $\begin{array}{l}\text { Top of inactive } \\
\text { volume } \\
\text { MCM }\end{array}$ & $\begin{array}{l}\text { Top of conserva- } \\
\text { tion volume } \\
\text { MCM }\end{array}$ & $\begin{array}{l}\text { Generation } \\
\text { efficiency } \\
\%\end{array}$ & No. of units & $\begin{array}{l}\text { Tail water } \\
\text { elevation } \\
\text { MSL }\end{array}$ \\
\hline Karun-4 & 1000 & 4 & 1405 & 2232 & 93 & 4 & 847 \\
\hline Karun-3 & 2000 & 4 & 1098 & 2718 & 93 & 8 & 670 \\
\hline Karun-1 & 2000 & 4 & 1095 & 2443.6 & 90 & 8 & 365 \\
\hline Masjed-Soleyman & 2000 & 4 & 181 & 226 & 90 & 8 & 233 \\
\hline Gotvand & 1500 & 4 & 1610 & 4671 & 92 & 4 & 90 \\
\hline Dez & 520 & 4 & 683 & 2909 & 89 & 8 & 175 \\
\hline
\end{tabular}


demand. This software can solve the problem using genetic algorithms based on NSGA-II optimization algorithm. It offers a user-friendly interface to set up the optimization problem and configure the algorithm (Savić et al. 2011). NSGA-II is a fast sorting and elite multi-objective genetic algorithm. Process parameters such as cutting speed, feed rate and rotational speed are the considerable conditions in order to optimize the machining operations in minimizing or maximizing the machining performances.

In order to link WEAP simulation model and optimization model, a code was written in Excel VBA so that it can be executed by GANetXL. To evaluate the objective function, the code calculates objective functions and passes it to the GANetXL.

Equations (1)-(3) represent the objective functions for both scenarios, and Eqs. (4)-(6) show the constraints.

Objective $1 \rightarrow \min Z_{1}=\sum_{j=1}^{m} \sum_{i=1}^{n}\left(\text { UnmetAgriDemand }_{i j}\right)^{2}$

Objective 2(scenario 1) $\rightarrow \min _{2}=\sum_{j=1}^{l} \sum_{i=1}^{n}\left(\text { UnmetEnergyDemand }_{i j}\right)^{2}$

Objective 2 (scenario 2$) \rightarrow \min Z_{2}$

$=\sum_{i=1}^{n}\left(\text { UnmetSystemEnergy Demand }_{i}\right)^{2}$

$S_{t, i}=S_{t-1, i}+I_{t, i}-R_{t, i}^{\mathrm{Re} q}-L_{t, i}$

$S_{t, i} \leq K_{i}$

$P_{i, t}=\operatorname{MIN}\left(K \cdot Q_{i, t} \cdot \bar{H}_{i, t} \cdot e_{i}\left(Q_{i, t}, \bar{H}_{i, t}\right), P_{i, \max }\right)$ where $m$ is the number of agricultural demand sites (three demand sites), $n$ is total number of time steps (396 months), and $i$ is total number of reservoirs (6 reservoirs). And also, $\mathrm{S}_{\mathrm{t}, \mathrm{i}}$ is the storage during period $t$ and site $i ; \mathrm{I}_{\mathrm{t}, \mathrm{i}}$ is amount of runoff during period $t ; R_{t, i}^{\mathrm{Req}}$ is amount of demand during period $t$ and site $i$; $\mathrm{L}_{\mathrm{t}, \mathrm{i}}$ is amount of loss during period $t$ and site $i$; and $K_{i}$ is maximum volume of reservoir $i$. And, $P_{i, t}$ is the power output; $Q_{i, t}$ is the water flowing through the turbine (release rate); $\bar{H}_{i, t}$ is the mean effective head; $e_{i}\left(Q_{i, t}\right.$, $\left.H_{i, t}\right)$ is the plant efficiency as a function of $Q_{i, t}$ and $\bar{H}_{i, t} ; K$ is a water to electricity conversion ratio; and $P_{i, \max }$ is the maximum generation capacity of the power plant.

\section{Results}

\section{Multi-objective optimization for decision making (Pareto front)}

As shown in Fig. 3, the convergence of the objective function is increased as the number of generations rise. However, in both scenarios, there is no considerable change in the objective function during the last generations. Also distribution of Pareto front is even in the last generations. Therefore, it can be concluded that the optimization is converged. The system performance is explored in two extreme points of Pareto front (the best point for agricultural water coverage and best point for hydropower), and then, the two scenarios are compared.

\section{Extreme points in scenario 1}

According to the reliability indices shown in Table 2, it can be concluded that there is no significant difference in the reliabilities of the demands in the optimal points. However,
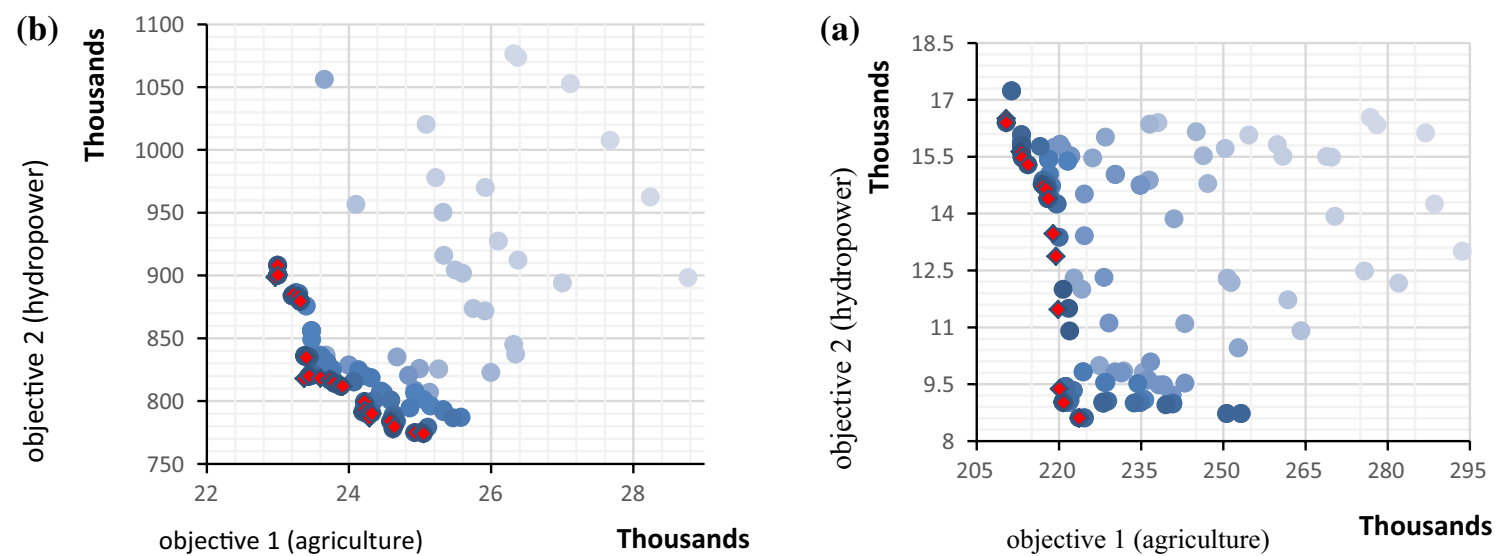

Fig. 3 Convergence of objective function in scenario 1 (a) and scenario 2 (b) 
Table 2 Reliability of the system in two extreme points of scenario 1

\begin{tabular}{lll}
\hline Reservoirs & \multicolumn{2}{l}{ Reliability of energy demand (\%) } \\
\cline { 2 - 3 } & Hydropower optimum & Agriculture optimum \\
\hline Dez & 85.4 & 84.8 \\
Masjed-Soleyman & 89.4 & 88.9 \\
Gotvand & 96 & 96.2 \\
Karun 1 & 89.9 & 89.1 \\
Karun 3 & 72.2 & 71.7 \\
Karun 4 & 63.4 & 62.9 \\
Whole system & 85.9 & 81 \\
\hline Agricultural demand & Reliability of agriculture demand (\%) \\
\cline { 2 - 3 } & Hydropower optimum & Agriculture optimum \\
\hline D1 & 93.2 & 94.4 \\
D2 & 76.8 & 76.5 \\
D3 & 93.4 & 94.4 \\
\hline EF demand & Reliability of environmental demand (\%) \\
\cline { 2 - 3 } & Hydropower optimum & Agriculture optimum \\
\hline Environmental flow 1 & 83.6 & 82.3 \\
Environmental flow 2 & 99.2 & 99.5 \\
\hline
\end{tabular}

Table 3 Reliability of the system in two extreme points of scenario 2

\begin{tabular}{|c|c|c|}
\hline \multirow[t]{2}{*}{ Reservoirs } & \multicolumn{2}{|l|}{ Reliability of energy demand } \\
\hline & Hydropower optimum & Agriculture optimum \\
\hline Whole system & 91.4 & 89.6 \\
\hline \multirow[t]{2}{*}{ Agricultural demand } & \multicolumn{2}{|c|}{ Reliability of agriculture demand } \\
\hline & Hydropower optimum & Agriculture optimum \\
\hline D1 & 94.2 & 94.7 \\
\hline D2 & 79.7 & 81.3 \\
\hline D3 & 94.2 & 94.7 \\
\hline \multirow[t]{2}{*}{ EF demand } & \multicolumn{2}{|c|}{ Reliability of environmental demand } \\
\hline & Hydropower optimum & Agriculture optimum \\
\hline Environmental flow & 182.6 & 83.3 \\
\hline Environmental flow & 298.5 & 99.5 \\
\hline
\end{tabular}

in general, reliabilities of energy and environmental flow demand are higher in hydropower optimum points. The whole system reliability for energy demand is almost $86 \%$.

\section{Extreme points in scenario 2}

From the results in Table 3, it can be seen that the system has a better performance in terms of hydropower generation and hydropower optimum point, while the reliability of agricultural and environmental demands is higher in (Table 3).

\section{Comparing two scenarios}

The system reliabilities in power production are $85.9 \%$ (scenario 1) and $91.4 \%$ (scenario 2). Similarly, for agriculture demand, scenario 2 has a better performance. However, there is not much difference between the two scenarios concerning the environmental flow supply. Therefore, of the two different scenarios considered, only scenario 2 is properly demonstrated. Figure 4 shows average monthly coverage of agricultural demands in scenario 2. D2 has the least coverage especially in August to December. That is due to low annual flow that enters into only one reservoir locating on Dez River which makes the system performance relatively low compared to Karun Tributary. According to Tables 2 and 3 , scenario 2 is more efficient than scenario 1 .

Time duration curves for power generation and unmet energy demand in both scenarios are shown in Figs. 5 and 6 , respectively. Also shortages of energy supply are much smaller in scenario 2 . From these figures, it can be generally concluded that scenario 2 has a better performance in water supply and energy production.

Average monthly hydropower generations and energy demand for scenario 2 are illustrated in Table 4.

The share of electricity in the total final energy production from March to July is more than $2000 \mathrm{GWH}$. The system has least power production (nearly $1000 \mathrm{GWH}$ ) between September and November leading to an impending power supply shortage. In addition, in Karun tributary moving from upstream to downstream, power production in reservoirs is increased due to more regulated regime for downstream reservoirs and difference between installed capacities.

\section{Conclusion}

In this study, a simulation-optimization model is developed by using WEAP and GANetXL optimization tool for Karun multi-reservoir system. The model uses two-objective NSGA-II algorithm in order to minimize water shortages in agricultural and energy demand supply. Two scenarios for energy demands are defined: a separate energy demand for each reservoir (scenario 1) and total energy demand for the total system power (scenario 2). Results showed that the scenario 2 has better performance in terms of reliability $(91.4 \%$ compared to $89.6 \%$ ) and efficiency of centralized approach in which all reservoirs are operated in an integrated management scheme. The reason is that in the second scenario, reservoirs cooperate and use integrated rules to supply system demand, while in the first scenario, they act individually to cover the energy demand defined for them. Currently three 
Fig. 4 Average agricultural demand $(\%)$ by scenario 2
Fig. 5 Energy duration curves for both scenarios
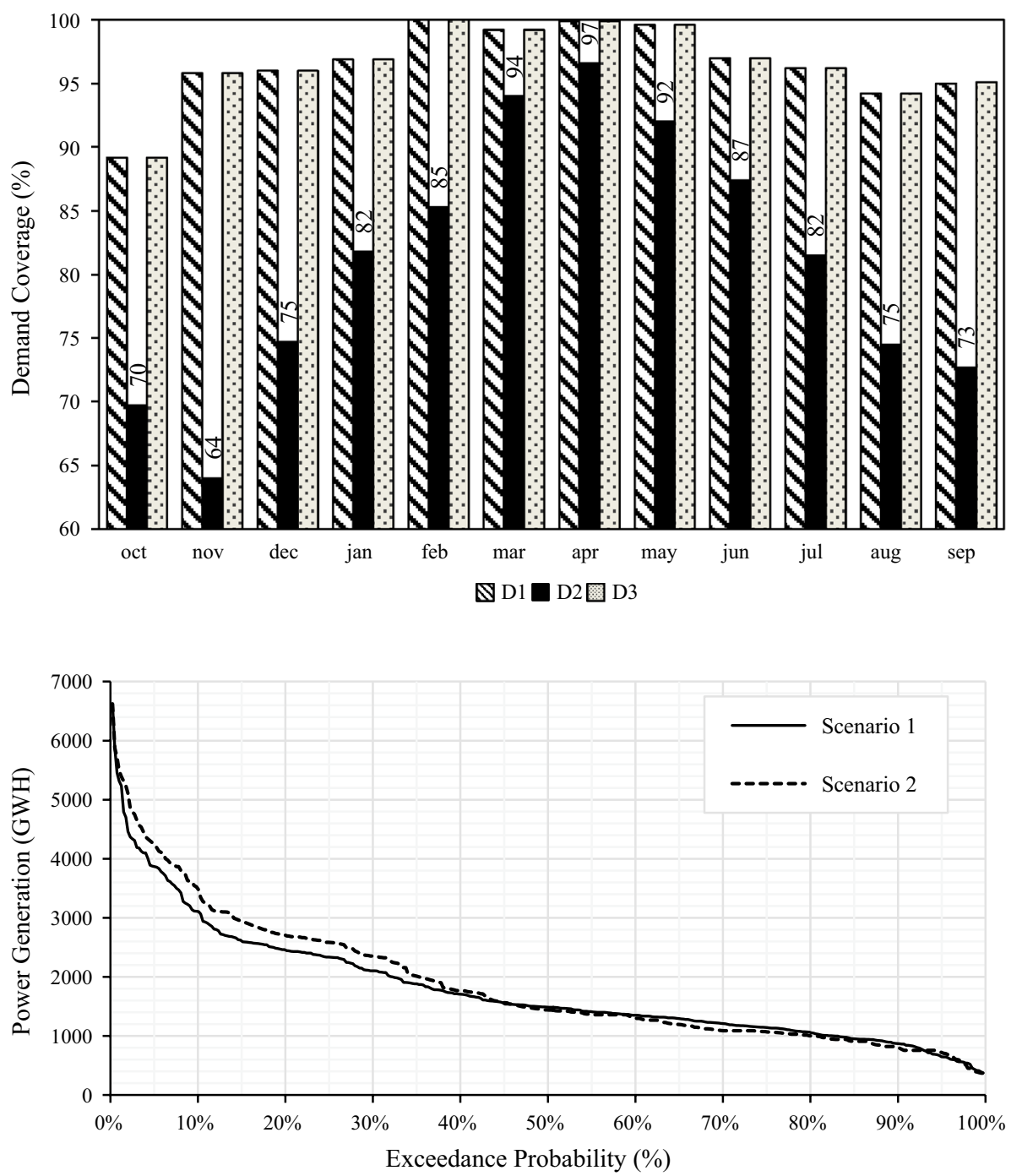

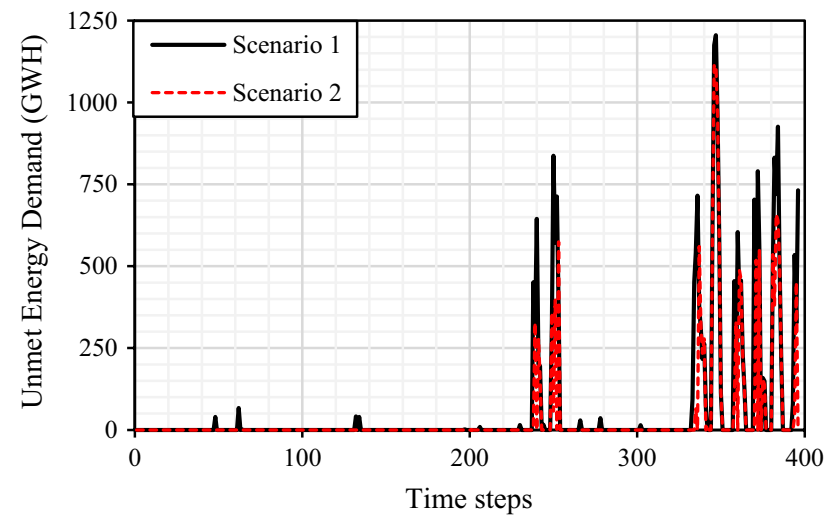

Fig. 6 Unmet energy demand loads the simulation time steps in both scenarios different organizations have the authority to operate these reservoirs. This research confirms that benefits from the system can be risen if the authorities cooperate.

Developed simulation-optimization approach is having great capacity in long-term systemic planning and operation studies of multi-reservoir systems. It also has the ability to be used in midterm and short-term operation studies ranging with weekly or daily time steps. In this regard, they can benefit from the foresight achieved from long-term simulations. 
Table 4 Average monthly hydropower generation for scenario $2(\mathrm{GWH})$

\begin{tabular}{|c|c|c|c|c|c|c|c|c|c|c|c|c|c|}
\hline & Oct & Nov & Dec & Jan & Feb & Mar & Apr & May & Jun & Jul & Aug & Sep & Sum \\
\hline Dez & 178 & 161 & 138 & 162 & 197 & 332 & 305 & 324 & 273 & 255 & 217 & 216 & 2760 \\
\hline Masjed-Soleiman & 192 & 191 & 242 & 281 & 312 & 525 & 551 & 476 & 331 & 391 & 336 & 263 & 4092 \\
\hline Gotvand & 221 & 209 & 246 & 299 & 345 & 518 & 531 & 517 & 398 & 467 & 382 & 329 & 4462 \\
\hline Karoun 1 & 220 & 213 & 266 & 304 & 356 & 591 & 639 & 536 & 360 & 438 & 372 & 298 & 4594 \\
\hline Karoun 3 & 123 & $\square 193$ & 242 & 237 & 297 & 486 & 545 & 499 & 316 & 335 & 315 & 187 & 3776 \\
\hline Karoun 4 & 55 & 91 & 123 & 105 & 175 & 296 & 353 & 310 & $\square 176$ & 136 & 279 & 62 & 2162 \\
\hline Sum & 989 & 1058 & 1258 & 1388 & 1682 & 2748 & 3235 & 2662 & 1855 & 2022 & 1901 & 1356 & 22155 \\
\hline Sum of demands & 941 & 909 & 755 & 820 & 910 & 1087 & 1088 & 1029 & 1268 & 1818 & 1888 & 1360 & 13872 \\
\hline Coverage $(\%)$ & 89 & 96 & 98 & 98 & 100 & 99 & 100 & 100 & 96 & 97 & 94 & 96 & $97 *$ \\
\hline
\end{tabular}

*Average of monthly coverage $(\%)$
Open Access This article is distributed under the terms of the Creative Commons Attribution 4.0 International License (http://creativeco mmons.org/licenses/by/4.0/), which permits unrestricted use, distribution, and reproduction in any medium, provided you give appropriate credit to the original author(s) and the source, provide a link to the Creative Commons license, and indicate if changes were made.

\section{References}

Afzali R, Mousavi SJ, Ghaheri A (2008) Reliability-based simulation-optimization model for multireservoir hydropower systems operations: Khersan experience. J Water Resour Plan Manag 134(1):24. https://doi.org/10.1061/(ASCE)0733-9496

Deb K, Partap A, Agarwal S, Meyarivan T (2002) Fast and elitist multiobjective genetic algorithm: NSGA-II. IEEE Trans Evolut Comput 6(2):182-197. https://doi.org/10.1109/4235.996017

Eum HI, Simonovic SP (2010) Integrated reservoir management system for adaptation to climate change: the Nakdong River Basin in Korea. Water Resour Manage 24(13):3397-3417. https://doi. org/10.1007/s11269-010-9612-1

Eum HI, Vasan A, Simonovic SP (2012) Integrated reservoir management system for flood risk assessment under climate change. Water Resour Manage 26(13):3785-3802. https://doi. org/10.1007/s11269-012-0103-4

Fayaed SS, El-Shafie A, Jaafar O (2013) Reservoir-system simulation and optimization techniques. Stoch Environ Res Risk Assess 27(7):1751-1772. https://doi.org/10.1007/s00477-013-0711-4

Hassaballah K, Jonoski A, Popescu I, Solomatine DP (2012) Modelbased optimization of downstream impact during filling of a new reservoir: case study of Mandaya/Roseires reservoirs on the Blue Nile River. Water Resour Manage 26(2):273-293. https://doi. org/10.1007/s11269-011-9917-8

Hassanjabbar A, Saghafian B, Jamali S (2018) Multi-reservoir system management under alternative policies and environmental operating conditions. Hydrol Res. https://doi.org/10.2166/nh.2018.150

Johnson SA, Stedinger JR, Staschus K (1991) Heuristic operating policies for reservoir system simulation. Water Resour Res 27(5):673685. https://doi.org/10.1029/91WR00320

Karamouz M, Kerachian R, Zahraie B (2004) Monthly water resources and irrigation planning: case study of conjunctive use of surface and groundwater resources. J Irrig Drain Eng ASCE 130(5):391402. https://doi.org/10.1061/(asce)0733-9437

Khuzestan Water and Power Authority (2010) Study and executive projects of irrigation and drainage networks, Water Department (in Farsi)

Loucks DP (1997) Operating rules for multireservoir systems. Water Resour Res 33(4):839-852. https://doi.org/10.1029/96WR03745
Lund JR (2006) Drought storage allocation rules for surface reservoir systems. J Water Resour Plan Manage ASCE 132(5):395-397. https://doi.org/10.1061/(asce)0733-9496

Lund JR, Guzman J (1999) Derived operating rules for reservoirs in series or in parallel. Water Resour Plan Manag ASCE 125(3):143153. https://doi.org/10.1061/(ASCE)0733-9496

Malekmohammadi B, Zahraie B, Kerachian R (2010) A real-time operation optimization model for flood management in river-reservoir systems. Nat Hazards 53(3):459-482. https://doi.org/10.1007/ s11069-009-9442-8

Ngo LL, Madsen H, Rosbjerg D (2007) Simulation and optimisation modelling approach for operation of the Hoa Binh reservoir, Vietnam. J Hydrol 336(3):269-281. https://doi.org/10.1016/j.jhydr ol.2007.01.003

Ostadrahimi L, Mariño MA, Afshar A (2012) Multi-reservoir operation rules: multi-swarm PSO-based optimization approach. Water Resour Manage 26(2):407-427. https://doi.org/10.1007/s1126 9-011-9924-9

Randall D et al (1997) Water supply planning simulation model using mixed-integer linear programming "engine". J Water Resour Plan Manage ASCE 123(2):116-124. https://doi.org/10.1061/ (asce)0733-9496

Rani D, Moreira MM, Mourato S (2008) Preliminary analysis of Alvito-Odivelas reservoir system operation under climate change scenarios. In: Proceedings of drought management: scientific and technological innovations, Zaragoza, Spain, Options Méditerranéennes, Series A, vol 80, pp 133-138

Safavi HR, Darzi F, Mariño MA (2010) Simulation-optimization modeling of conjunctive use of surface water and groundwater. Water Resour Manage 24(10):1965-1988. https://doi.org/10.1007/s1126 9-009-9533-z

Savić DA, Bicik J, Morley MS (2011) A DSS generator for multiobjective optimisation of spreadsheet-based models. Environ Model Softw 26(5):551-561

Sedki A, Ouazar D (2011) Simulation-optimization modeling for sustainable groundwater development: a Moroccan coastal aquifer case study. Water Resour Manage 25(11):2855-2875. https://doi. org/10.1007/s11269-011-9843-9

Shokri A, Haddad OB, Mariño MA (2013) Algorithm for increasingthe speed of evolutionary optimization and its accuracy in multiobjectiveproblems. Water Resour Manage 27(7):2231-2249. https ://doi.org/10.1007/s11269-013-0285-4

Shourian M, Mousavi S, Tahershamsi A (2008) Basin-wide water resources planning by integrating PSO algorithm and MODSIM. Water Resour Manag 22(10):1347-1366. https://doi.org/10.1007/ s11269-007-9229-1

Sigvaldason OT (2010) Simulation model for operating a multipurpose multi-reservoir system. Water Resour Res 12(2):263-278. https:// doi.org/10.1029/WR012i002p00263 
Suiadee W, Tingsanchali T (2007) a combined simulation-genetic algorithm optimization model for optimal rule curves of a reservoir: a case study of the Nam on Irrigation Project, Thailand. Hydrol Process 21(23):3211-3225

Tejada-Guibert JA, Johnson SA, Stedinger JR (1993) Comparison of 2 approaches for implementing multireservoir operating policies derived using stochastic dynamic programming. Water Resour Res 29(12):3969-3980. https://doi.org/10.1029/93WR02277

Yates D, Sieber J, Purkey D, Huber-Lee A (2005) WEAP21-a demand-, priority-, and preference-driven water planning model: part 1: model characteristics. Water Int 30(4):487-500. https:// doi.org/10.1080/02508060508691893
Zhang JL, Li YP, Huang GH (2013) A robust simulation-optimization modeling system for effluent trading - a case study of nonpoint source pollution control. Environ Sci Pollut Res 1:1. https://doi. org/10.1007/s11356-013-2437-8

Publisher's Note Springer Nature remains neutral with regard to jurisdictional claims in published maps and institutional affiliations. 